\title{
Mechanical and Energy Engineering
}

\section{Numerical Study for the Tube Rotation Effect on Melting Process in Shell and Tube Latent Heat Energy Storage LHES System}

\author{
Mohammed Ibrahim Fathi \\ College of Engineering-University of Baghdad \\ Iraq, Baghdad \\ E-mail:m.fathi1003@coeng.uobaghdad.edu.iq
}

\author{
Munther Abdullah Mussa \\ Assist. Professor \\ College of Engineering-University of Baghdad \\ Iraq, Baghdad \\ E-mail:munther@coeng.uobaghdad.edu.iq
}

\begin{abstract}
Although renewable energy systems have become an interesting global issue, it is not continuous either daily or seasonally. Latent heat energy storage (LHES) is one of the suitable solutions for this problem. LHES becomes a basic element in renewable energy systems. LHES compensate for the energy lack when these systems are at low production conditions. The present work considered a shell and tube LHES for numerical investigation of the tube rotation influence on the melting process. The simulation and calculations were carried out using ANSYS Fluent software. Paraffin wax represents the phase change material (PCM) in this work, while water was selected to be the heat transfer fluid (HTF). The calculations were carried out for $9 \mathrm{rpm}$ tube rotation case as well as the stationary case. The results show a slight increase in the liquid content of phase change material PCM due to tube rotation. The enhancement percentage in liquid content was $3.5 \%$ for $6 \mathrm{hrs}$ charging process. The heat transfer in the axial direction was small relative to that in the radial direction.
\end{abstract}

Keywords: shell and tube, paraffin, rotation

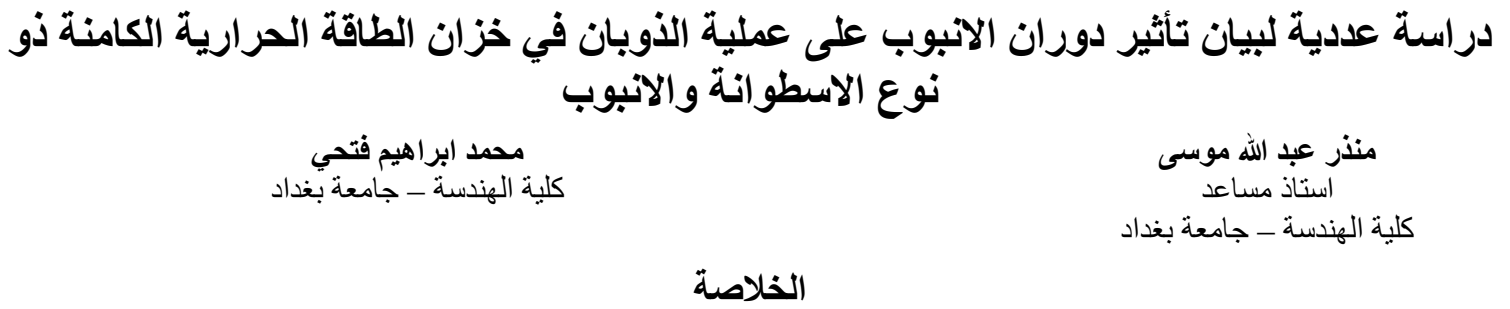

على الرغم من أن أنظمة الطاقة المتجددة أصبحت قضية عالمية مثيرة للاهتمام ، إلا أنها متذبذبة سواء خلال اليوم الو احد او على المدى الموسمي ـ يعد خزان الطاقة الحرارية الكامنة أحد الحلول المناسبة لهذه المشكلة. أصبح خزان إنهان

*Corresponding author

Peer review under the responsibility of University of Baghdad.

https://doi.org/10.31026/j.eng.2021.11.06

2520-3339 () 2019 University of Baghdad. Production and hosting by Journal of Engineering.

This is an open access article under the CC BY4 license http://creativecommons.org/licenses/by/4.0/2.

Article received: 5/8/2021

Article accepted: 13/9/2021

Article published:1/11/2021 


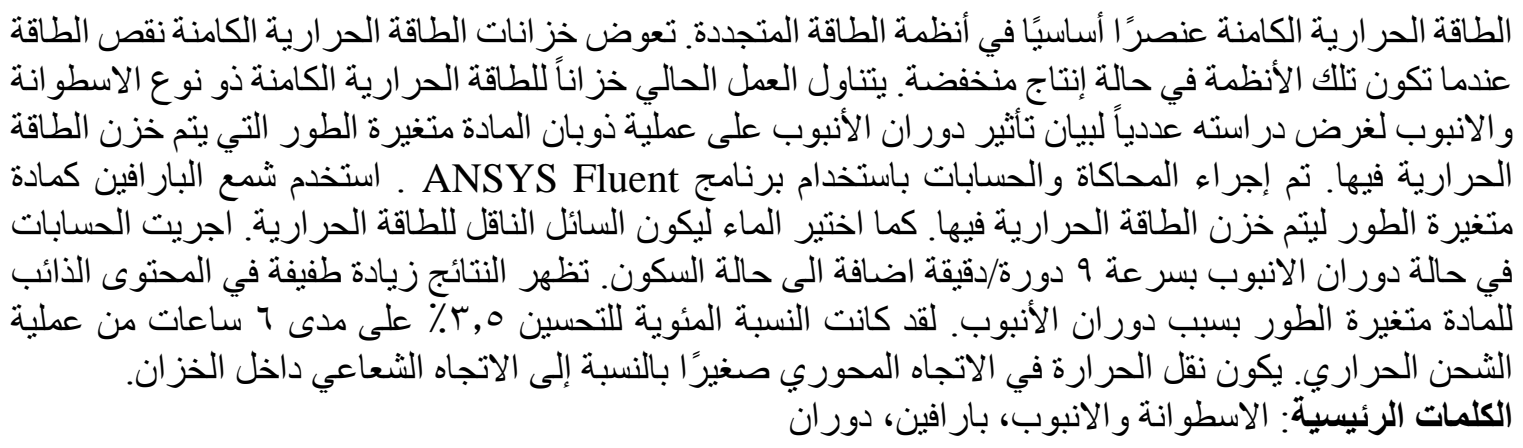

\section{INTRODUCTION}

Human societies nowadays are constantly looking for new energy sources due to the increasing energy demand. They found that the lack of energy may be compensated using renewable energy sources such as solar energy, wind energy, etc. Some of these renewable energy sources are not continuous during the day, and others are available seasonally. In such a situation, energy storage becomes necessary to solve this problem (Ebadi et $\boldsymbol{a l}$., 2018).

Energy storage is also beneficial in restoring industrial waste energy and utilizing it when needed (Miró, Gasia, and Cabeza, 2016).

There are many types of energy storage, like mechanical, chemical, electrical, and thermal storage (Nadeem et al., 2019). One of the typical types of energy storage is latent heat thermal energy storage which utilizes the latent heat of phase change materials. LHES becomes typical due to the advantages of PCM, which represents its basic element. PCMs should be of high latent heat relative to volume, non-toxic, and have chemical stability (Sharma et al., 2009).

From the preceding, it becomes clear the importance of energy storage in bridging the shortage of energy, so scientists and researchers tried their best to study and improve the performance of this type of energy storage.

Practically, PCM melted in temperature range but theoretically (for simplification), some researchers consider the constant melting temperature in their works. So, (Regin, Solanki, and Saini, 2006) investigated numerically and experimentally the melting process of PCM inside the cylindrical capsule to find out the difference in results between these two considerations. The effect of varying capsule radii on the melting process was studied as well. The experimental setup consists of aluminum cylindrical capsule, and the inner diameter, thickness, and length are $76 \mathrm{~mm}, 2 \mathrm{~mm}$, and $100 \mathrm{~mm}$, respectively. The capsule was filled with paraffin wax as PCM and was immersed in hot water. The results show that the percentage difference in results between melting temperature range and constant melting temperature is $20.7-15.6 \%$ for radii $20-60 \mathrm{~mm}$, respectively. The smaller the capsule radius, the shorter the melting time.

The orientation of the system was vertical in the study by (Akgün, Aydin, and Kaygusuz, 2007). Paraffin wax was used as PCM, and water was used as HTF. The shape of the shell was upside-down conical geometry because of the nature of molten PCM, which is raised to be in the upper region due to natural convection. The results show that the conical shape and high inlet temperature of HTF decrease melting time while the low HTF flow rate is favorable. 
Solidification and melting during charge and discharge processes in LHES were investigated by

(Hosseini et al., 2012) studied the behavior of PCM inside shell and tube LHES. The main parameter of the study is HTF inlet temperature. The study was carried out experimentally and numerically where the shell's inner diameter is $85 \mathrm{~mm}$ and $22 \mathrm{~mm}$ diameter copper tube. RT50 paraffin wax was used as PCM, and water was used as HTF. The results show that when the inlet temperature of HTF is $80 \mathrm{C}$, the melting time is reduced by $37 \%$.

(Avci and Yazici, 2013) investigated experimentally melting/solidification of PCM inside a horizontal shell and tube LHES. Paraffin wax represents the PCM in which fills the annular space between shell and tube. The tube is copper and convoys water as HTF. The results show that as PCM melts, it begins to rise to the upper region due to natural convection currents. Therefore, the temperature distribution will not be uniform during the melting/solidification process.

(Li and Kong, 2014) numerically studied the performance of shell and tube LHES during the charging process. The problem was simulated and solved using ANSYS Fluent software as a $2 \mathrm{D}$ problem. The diameters of shell and tube were $3 \mathrm{~cm}$ and $1 \mathrm{~cm}$, respectively. The study was implemented for two types of HTF, water, and air. The other parameter involved in this study was the velocity of HTF. Paraffin wax was used as PCM, which fills the space between shell and tube. The inlet temperature for both HTFs was 60C. The results show that in the case of air as HTF, the flow velocity affects positively and remarkably the heat transfer rate whereas, in the case of water as HTF, the flow velocity has very little effect on the performance of the LHES. Still, the heat transfer rate is larger than that in the air case.

A double pipe heat exchanger was considered by (Hosseini, Rahimi, and Bahrampoury, 2015) to serve as shell and tube LHES. They studied the effect of circular finned tubes experimentally and numerically. The study includes two fin heights which are $13 \mathrm{~mm}$ and $26 \mathrm{~mm}$. The shell has an inner diameter of $85 \mathrm{~mm}$, and the tube has an outer diameter of $22 \mathrm{~mm}$, while the system length was $1 \mathrm{~m}$. RT50 paraffin wax was used as PCM, and water was used as HTF. The results show that fin existence is of good effect on LHES performance. Increasing fins height helps deliver thermal energy to radially farther points and reduces the melting time during the charging process. The melting time is inversely proportional to the height of fins. Increasing fins height affects solidification time more than melting time.

(Senthil and Cheralathan, 2016) investigated the solidification and melting processes in shell and tube LHES. The test section is $500 \mathrm{~mm}$ long, and the shell and tube diameters are 100 and $25 \mathrm{~mm}$, respectively. The shell was insulated, and the tube was copper. Paraffin wax represents the PCM, and water is the HTF. The parameters of the study were HTF inlet temperature and the flow rate of HTF. The results show that the melting process at the lower region is ineffective due to convection currents that carry more thermal energy to the upper region. The increase in $\mathrm{HTF}$ inlet temperature by $5^{\circ} \mathrm{C}$ causes decreasing in melting time by $6.2 \%$. The rate of heat transfer increases with the increase of the flow rate of HTF. (Aydin et al., 2018) studied the enhancement of performance by adding fin on the bottom side of the tube in shell and tube LHES. The diameters of shell and tube were 110 and $28 \mathrm{~mm}$, respectively. The length of the system is $500 \mathrm{~mm}$. Paraffin wax was selected to be the PCM, and HTF was water. The study was implemented on four cases of fin height; 10, 
20,30 , and $40 \mathrm{~mm}$. The fin, in each case, was made of copper and its thickness is $1.5 \mathrm{~mm}$. The HTF inlet temperature and flow rate were fixed at $80 \mathrm{C}$ and $280 \mathrm{~kg} / \mathrm{h}$, respectively. The results show that fin existence causes remarkable influence towards reducing the melting time.

(Khan, Zhao and Xu, 2019) numerically studied the effect of a longitudinally finned tube of different geometries of fins on melting processes of horizontal LHES. The problem was simulated and solved as a 2D model using ANSYS Fluent software. The parameters used to assess the performance of LHES were the number of fins, fins height, and fins thickness. The calculations were carried out for a number of fins 4, 6, and 8, fins heights 5, 15, and $25 \mathrm{~mm}$, and fins thickness 5,10 , and $15 \mathrm{~mm}$. The work involved two types of paraffin as PCMs; RT50 and C58. The PCM fills the annular space between shell and tube, and the boiling water was assumed to be the HTF. The results show that the melting rate in the case of C58 is slower than that in the case of RT50. That means the melting rate becomes slow with the increase of PCM viscosity, as C58 is more viscous than RT50. Increasing both the number and height of fins leads to improve the performance of the LHES significantly.

In the preceding review, some researchers studied the behavior of LHES, and the other researchers concerned with enhancement techniques for the LHES. In terms of enhancement, some researchers have proposed to involve the rotational motion with LHES system to be one of the enhancement methods.

(Herrick and Zarnoch, 1980) investigated the heat exchange between rolling (rotating) cylinder filled with melted PCM and airflow past it. The cylinder was placed horizontally on rollers to be free to rotate. It was surrounded by a wooden box that had two openings, one for the air inlet and the other for the air outlet. As the air enters and leaves the wooden box, it extracts the thermal energy from the rolling cylinder. The basic objective is to investigate the effect of rolling (rotation) motion on PCM solidification inside the cylinder. The direction of the air stream is the same direction of the axis cylinder. The size of the cylinder is 6in outer diameter and 12in length. Glauber's salt was used as PCM, which is an inorganic material. The results show that rotation (rolling) helps to stir melted PCM inside a cylinder. Therefore, the temperature distribution inside the rolling cylinder is uniform. Consequently, the heat transfer was enhanced remarkably.

(Kurnia and Sasmito, 2018) numerically examined the effect of rotation on the performance of LHES. Shell and tube type LHES was under test. The physical model includes a shell with $25.8 \mathrm{~mm}$ inner diameter and a tube with $12.7 \mathrm{~mm}$ inner diameter and $15.8 \mathrm{~mm}$ outer diameter. Paraffin acts as PCM and water as HTF. The problem was simulated using ANSYS Fluent software to solve the problem by the enthalpy porosity method. Three rotational speeds were applied to implement the study, which were 0.25 , 0.5 , and $1 \mathrm{rpm}$. The results show that enhancement of $25 \%$ and $41 \%$ were obtained in charging and discharging processes, respectively, compared with the stationary condition. (Selimefendigil and Öztop, 2020) utilized the rotation motion by putting an adiabatic rotating cylinder in a rectangular cavity contains PCM. The heat source is the high temperature of the left side of the cavity, which causes the PCM to melt. The problem was simulated and solved numerically as a 2D problem using ANSYS Fluent software. The solution begins when the melt front traverses the cylinder towards the cold side. The results show that the heat transfer rate from left to right increases by a noticeable value in cylinder rotation. 
(Fathi and Mussa, 2021) studied the effect of tube rotation on the behavior of PCM in shell and tube LHES during the charging process experimentally. The shell has an inner diameter of $125 \mathrm{~mm}$ and a tube diameter of $28.5 \mathrm{~mm}$. Paraffin wax represents the PCM, and water represents the HTF. The speed rotation ranged between 3-9rpm. The results showed that tube rotation is weak and confined to distort the convection currents at the upper region with this range.

Using the rotating mechanism as a method to improve the melting behavior has not been thoroughly investigated. This study's objective is to numerically inspect the behavior of the melting process when the HTF tube is in a rotation state. The present numerical work is an extension of the experimental work of (Fathi and Mussa, 2021). In experimental work, the performance is externally inferred using a number of sensors, so the internal behavior details are few. In contrast, the numerical simulation gives more information about the internal behavior of PCM. Therefore, this work aims to numerically resolve the experimental work for more knowledge about the effect of tube rotation on the performance of LHES. The system under consideration is shell and tube LHES in a horizontal position. The typical working principle is that the HTF which is water receives thermal energy from any thermal source. HTF convoys this energy to be stored as latent heat in PCM. The thermal energy transfers from HTF to PCM across the tube by conduction.

\section{PHYSICAL MODEL}

Fig. 1 shows a schematic diagram of the physical model used in the numerical investigation of the present work. It is two concentric cylinders; the outer cylinder represents the wall of the shell, while the thick inner cylinder represents the HTF tube. The diameter of the shell is $0.113 \mathrm{~m}$, and the large diameter of the tube is $0.028575 \mathrm{~m}$, and its thickness is $0.00065 \mathrm{~m}$. The length of the system is $0.54 \mathrm{~m}$. The annular volume is filled with paraffin wax as PCM while HTF, which is water, flows inside the tube. The tube material is copper. The physical properties of paraffin wax are listed in Table 1 (Fathi and Mussa, 2021).

Thermal properties of water and copper were assumed to be constant and listed in

\section{Table 2.}




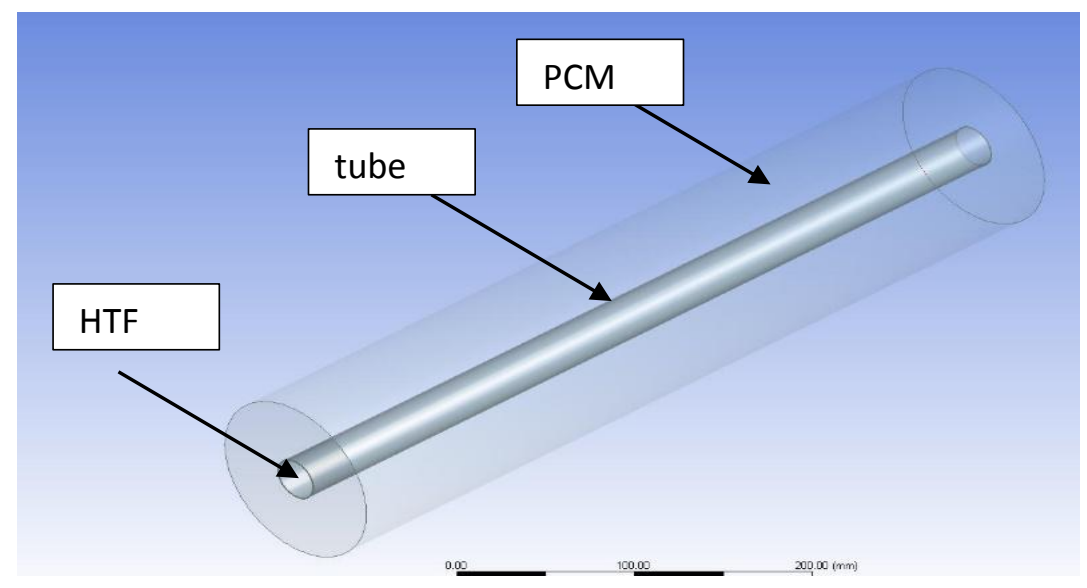

Figure 1. Physical model.

Table 1. Physical properties of PCM.

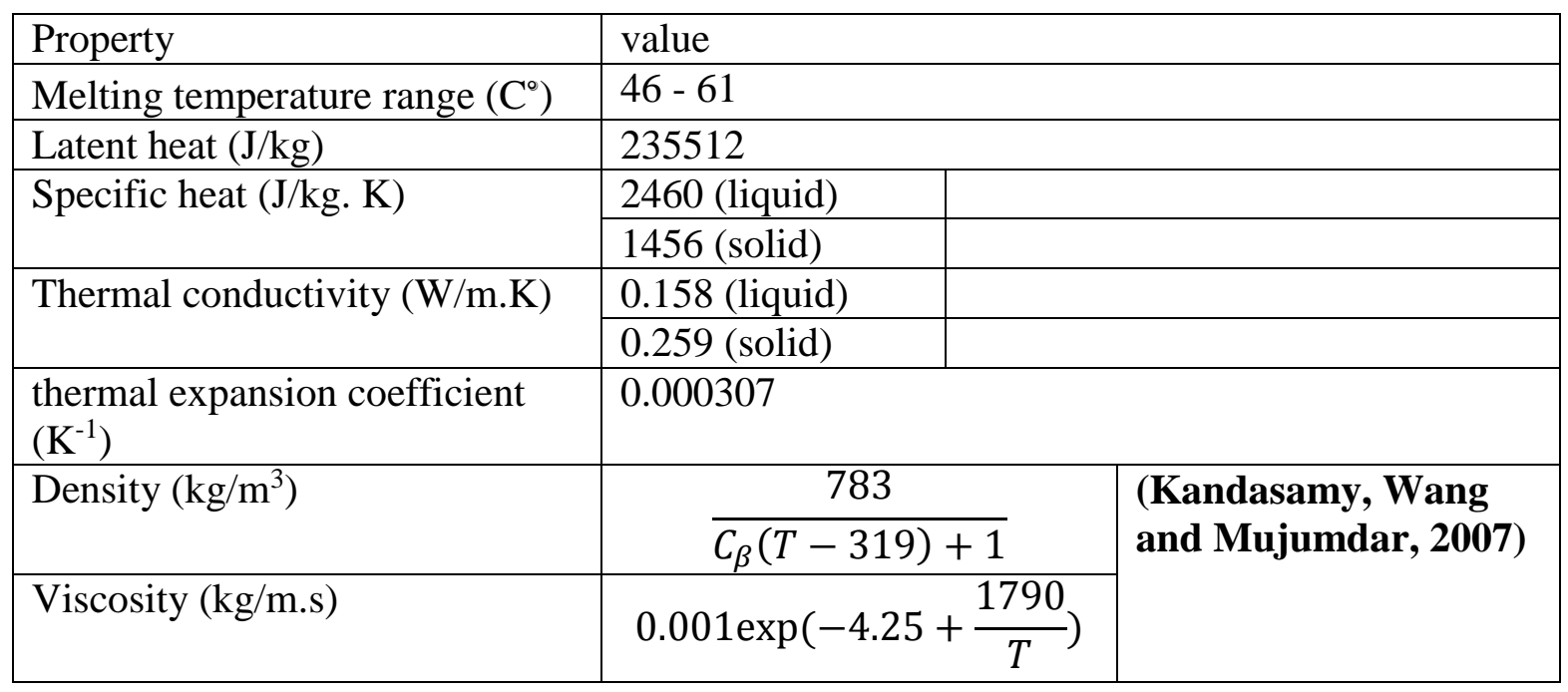

Table 2. Physical properties of water and copper.

\begin{tabular}{|l|l|l|}
\hline Property & \multicolumn{2}{|c|}{ value } \\
\hline & water & copper \\
\hline Density $\left(\mathrm{kg} / \mathrm{m}^{3}\right)$ & 998 & 8978 \\
\hline Thermal conductivity (W/m.K) & 0.6 & 387 \\
\hline Specific heat $(\mathrm{J} / \mathrm{kg} . \mathrm{K})$ & 4180 & 380 \\
\hline Viscosity $(\mathrm{kg} / \mathrm{m} . \mathrm{s})$ & 0.001003 & \\
\hline
\end{tabular}




\section{Number 11 Volume 27 November $2021 \quad$ Journal of Engineering}

\section{ASSUMPTIONS}

Different activities and processes are involved in the system of present work. Therefore, many assumptions were put as follows:

- The PCM is homogenous, and its properties are isotropic.

- Natural convection in molten PCM due to density change and gravity action was considered.

- Flow due to convection in molten PCM is laminar.

- All PCM domain has the same initial temperature.

- No heat generation.

- Radiation effect was neglected.

- The flow of HTF is laminar, incompressible, and Newtonian.

- Constant tube rotational speed.

\section{GOVERNING EQUATIONS}

Since this work includes melting/solidification processes, the enthalpy porosity method is used to solve this problem. This method is typically used in such problems. The absolute velocity formulation is used in the present work. As this problem includes rotation motion, the moving reference frame was used as a coordinate system. For the moving reference frame, the mass, momentum, and energy equations are as follows (Kurnia and Sasmito, 2018):

$$
\begin{aligned}
& \frac{\partial \rho_{p c m}}{\partial t}+\nabla \cdot\left(\rho_{p c m} \mathbf{v}_{\mathbf{r}}\right)=0 \\
& \begin{array}{r}
\frac{\partial\left(\rho_{p c m} \mathbf{v}\right)}{\partial t}+\nabla \cdot\left(\rho_{p c m} \mathbf{v}_{\mathbf{r}} \mathbf{v}\right)+\rho_{p c m}\left[\omega \times\left(\mathbf{v}-\mathbf{v}_{\mathbf{t}}\right)\right] \\
=-\nabla \cdot p \mathbf{I}+\nabla \cdot\left[\mu_{p c m}\left(\nabla \mathbf{v}+(\nabla \mathbf{v})^{T}\right)\right]+\rho \mathbf{g}+\mathbf{S}_{\mathbf{m o m}}
\end{array} \\
& \frac{\partial}{\partial t}\left(\rho_{p c m} H_{p c m}\right)+\nabla \cdot\left(\rho_{p c m} \mathbf{v}_{\mathbf{r}} H_{p c m}\right)=\nabla \cdot\left(k_{p c m} \nabla T\right)
\end{aligned}
$$

Source term was added to momentum equation in order to make sense for deviation of both solid and liquid fields. Also, the energy equation gets its own source term to evaluate the growth of latent heat (Irwan, Nor Azwadi, and Asako, 2019).

The enthalpy porosity formulation depends on the enthalpy property in the energy equation, so the enthalpy which appears in Eq. (3) is:

$$
H_{p c m}=h_{p c m}+\Delta H_{p c m}
$$

$\mathrm{h}_{\mathrm{pcm}}$ is the sensible heat. It is: 


$$
h_{p c m}=\int_{T<T_{S}}^{T} c_{p} \rho_{p c m} d T+\int_{T}^{T>T_{l}} c_{p} \rho_{p c m} d T
$$

and:

$$
\Delta H_{p c m}=\beta L
$$

where $\mathrm{L}$ is the latent heat of PCM and $\beta$ is liquid fraction is expressed as:

$$
\beta=\left\{\begin{aligned}
0, & T<T_{s} \\
\frac{T-T_{s}}{T_{l}-T_{s},} & T_{l}<T<T_{s} \\
1, & T>T_{l}
\end{aligned}\right.
$$

Then, according to Eq. (6), liquid fraction plays a role in calculating transmission from solid phase to liquid phase across interface region, also called the mushy zone.

The source term $S_{\text {mom }}$ in Eq. (2) can be expressed by:

$$
S_{m o m}=\frac{(1-\beta)^{2}}{\left(\beta^{3}-\varepsilon\right)} C \mathbf{v}_{\mathbf{r}}
$$

where $\mathrm{C}$ is the mushy zone constant, and $\varepsilon$ is a small value to avoid division by zero. The value of $\mathrm{C}$ is between $10^{4}$ and $10^{7}$, but $10^{5}$ was used here.

The melting process problem in horizontal shell and tube LHES is to be solved. A transient numerical solution for the problem of the present work will be implemented using ANSYS Fluent 15 software which is capable of solving melting/solidification problems by enthalpy-porosity technique. Also, this software uses the finite volume method FVM over the problem domains. 3D model of this problem was simulated by the feature of this software to investigate the effect of rotation on the melting time of PCM.

\section{NUMERICAL MODEL}

The meshing tool in ANSYS Fluent 15 software is an efficient tool for meshing physical models. All edges in the model are divided into a number of divisions. The axial direction is also divided (sweep) into a number of divisions. The meshing tool has a feature to select radial divisions according to angular (edges) divisions and axial divisions so that each cell has a consistent aspect ratio. All the numbers of divisions are listed in Table 3. The mapped hexahedral mesh was used for meshing the PCM and tube domains, while free hexahedral mesh was used for meshing the HTF domain. The test model was meshed as in Fig. 2. 

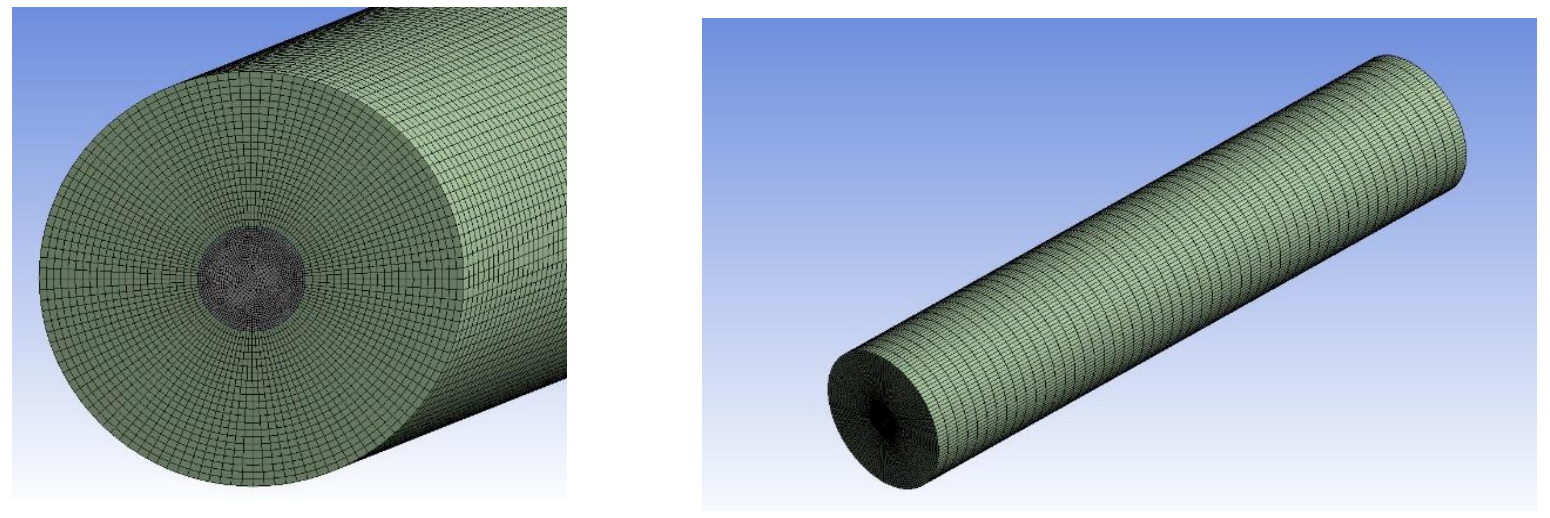

Figure 2. Meshed model.

\section{INITIAL AND BOUNDARY CONDITIONS}

The initial temperature of the system for all cases was assumed to be equal to environment temperature, which is about $300 \mathrm{~K}$, whereas the boundary conditions are as follows:

1 - Both ends of the annulus and outer shell of the test model were treated as thermally insulated walls (Fig. 3).

2- Two individual cases will be under study:

a- Still case in which shell and tube have rotation speed value equal to zero.

b- Tube rotation case in which 9rpm rotational speed will be applied on the tube.

3 - HTF enters to the storage at $356 \mathrm{~K}$ with flow rate $0.014 \mathrm{~kg} / \mathrm{s}$.

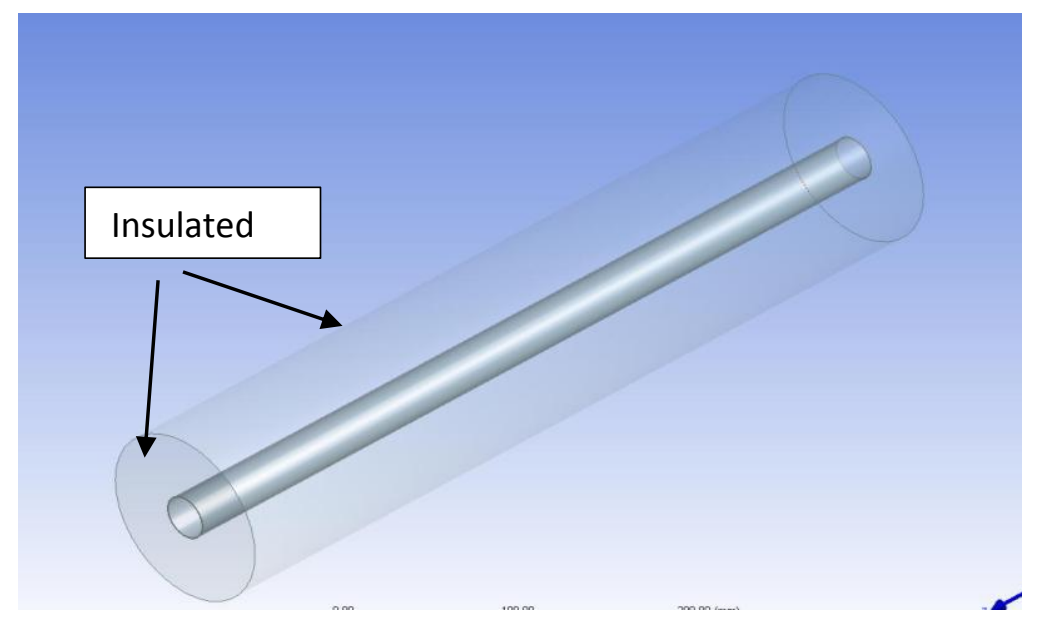

Figure 3. Boundary condition of shell and its ends. 


\section{MESH INDEPENDENCE}

A number of calculation runs in still cases were implemented to select a suitable grid size of the mathematical model. Grid sizes are listed in Table 3, and its results are plotted in Fig. 4.

From Fig. 4 and Table 3, it can be seen that grids No. 2 and 3 are congruent, so that grid No. 2 can be adopted because it is less elements. Increasing grid size as in grid No. 4 did not add much more change in a long period of the test; besides, it is consuming more computational time. Due to the above reasons, grid No. 2 was selected to complete calculations in this project.

Table 3. Mesh sizes.

\begin{tabular}{|l|l|l|l|l|l|}
\hline No. & $\begin{array}{l}\text { Angular } \\
\text { divisions }\end{array}$ & $\begin{array}{l}\text { Radial PCM } \\
\text { divisions }\end{array}$ & $\begin{array}{l}\text { Axial } \\
\text { divisions }\end{array}$ & $\begin{array}{l}\text { Number of } \\
\text { elements }\end{array}$ & \\
\hline 1 & 90 & 17 & 54 & 143154 & \\
\hline 2 & 120 & 22 & 54 & 223236 & \\
\hline 3 & 120 & 22 & 70 & 298200 & \\
\hline 4 & 150 & 28 & 54 & 371790 & \\
\hline
\end{tabular}

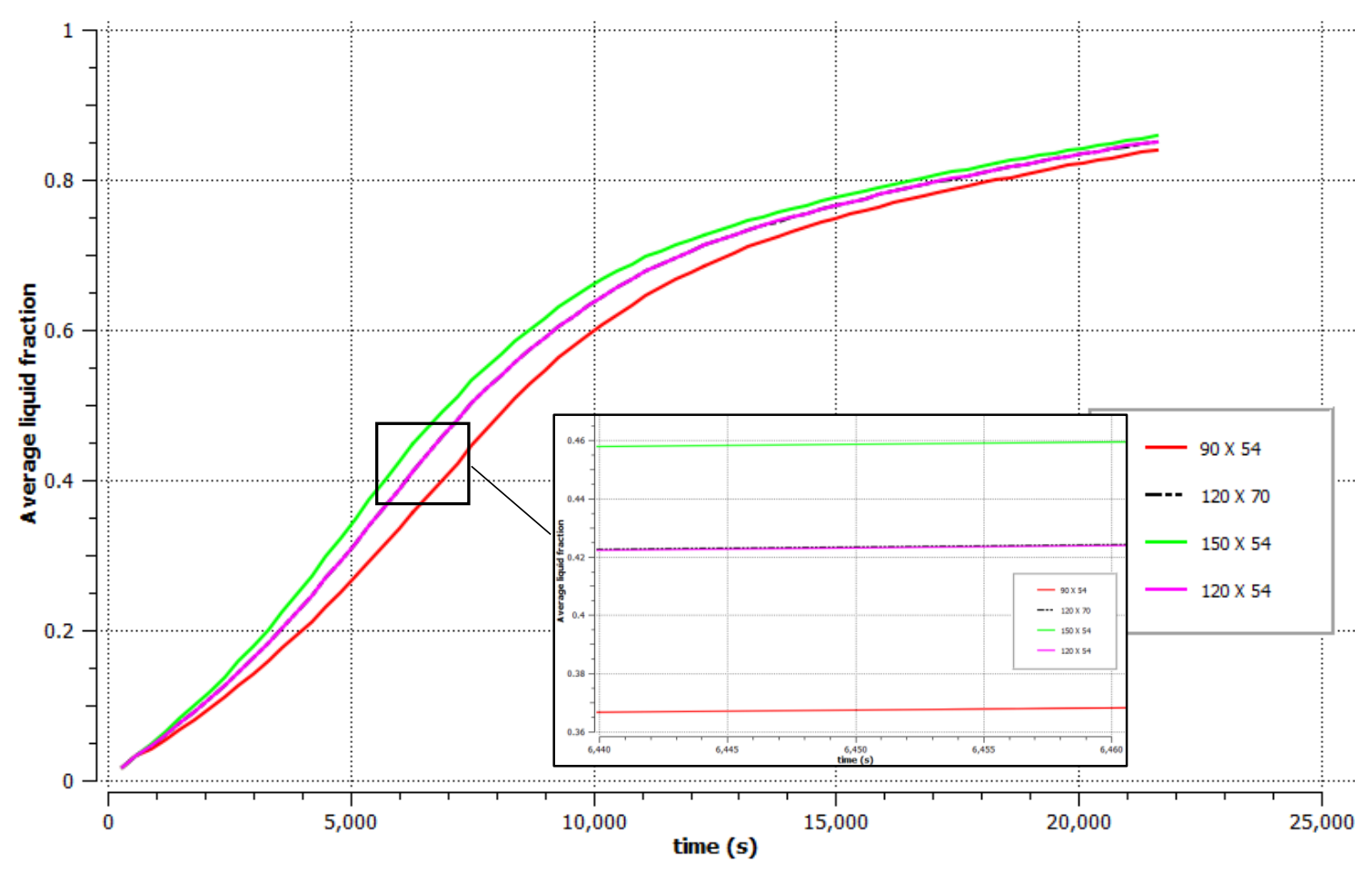

Figure 4. Mesh independence. 


\section{NUMERICAL TREATMENT}

The convergence criteria for energy was $10^{-9}$, while the momentum of all directions was $10^{-7}$. After many run attempts, it was found that the set of under-relaxation factors of (Soibam, 2017) is suitable in this work to avoid divergence. Those for pressure, density, and Body Forces were 0.3, 0.8, and 1, while momentum, liquid fraction, and energy were $0.3,0.1$, and 0.9 .

At the step of solution method, the pressure was corrected using the PRESTO scheme and pressure-velocity coupling implemented by Semi IMplicit Pressure Linked Equation (SIMPLE) algorithm. The Time step was set to be 1 second, and the number of iterations is 20 for each time step. The values of physical properties in Table $\mathbf{1}$ have been written in a file as a user-defined material then copied to FLUENT software. The properties that depend on temperature were fed as a user-defined function.

\section{RESULTS AND DISCUSSION}

A horizontal shell and tube LHES were under focus to study the effect of tube rotation on the performance of LHES. Numerical simulations for both still cases and tube rotation cases were carried out.

\subsection{Axial Variation of Liquid Fraction Contours}

As shown in Fig. 5, planes were specified and prepared to plot liquid fraction contours. These planes are located at the entrance, mid, and exit of LHES, respectively. They are perpendicular to the axial axis of LHES.

For still cases, Fig. 5 depicts the liquid fraction distribution inside LHES at specified planes. It can be noticed that at the beginning period, the area of the liquid fraction at the entrance is larger than its area at other locations. That is because of the large temperature gradient between HTF and PCM at the entrance. The HTF is loaded with maximum thermal energy at the entrance and reaches the exit after release a reasonable amount of its energy in PCM. This behavior gradually disappears when the melt front reaches just below the centerline. After that, at the final period, the melting rate is similar from the entrance to exit inside the PCM field.

In Fig. 6, for the tube rotation case, the behavior of PCM is similar to that in the still case at all specified planes. But the areas of liquid PCM in the first period were smaller. That is because the rotation of the tube leads to weakening the convection currents. This phenomenon will be discussed in detail in sections 10.3, 10.4, and 10.5.2.

It is evident from section 10.1 that the heat transfer is small in the axial direction relative to the radial direction. This is the same result reached by (Agyenim, Eames, and Smyth, 2011). So, a plane at mid-distance will be considered to show the transient behavior of the PCM field.

\subsection{Still System Case}

The contours of the average liquid fraction are plotted in Fig. 7a for different periods. In the beginning, it can be seen that PCM begins to melt uniformly around and just close to the HTF tube. After a while, the amount of liquid PCM became enough to activate the gravity action. The gravity action motivates the natural convection due to density variation. 


\section{Number 11 Volume 27 November $2021 \quad$ Journal of Engineering}

Finally, most of the upper region became liquid, and inversely, the lower region is still solid.

\subsection{Tube Rotation Case}

Referring to Fig. $\mathbf{7 b}$, as in the still case, the melting process starts in the region very close to the HTF tube. PCM receives thermal energy by conduction until enough liquid PCM is formed, then natural convection takes place. As the melting process progresses, the liquid region enlarges, gradually attempting to occupy the upper storage region. For a specific time step (after about 5700 seconds), it can be seen that area of liquid PCM is less than its opposite area is still the case and skewing to the left side, that is because a velocity component was generated due to HTF tube rotation impairs the velocity component of natural convection. So, the tube rotation causes a difference between the two sides of the cross-section of storage. At the end of the run, the difference between the still and tube rotation cases is small for the same working time.

\subsection{The Influence of Tube Rotation}

Recalling Fig. 7 again, the area of liquid PCM in the still case is the largest due to the natural convection effect, while the tube rotation seems to have a negative effect (due to the angular component in the liquid PCM). This mode continues until a time of 16,500 seconds. At this time, an adequate amount of PCM liquid has been formed beneath the rotating tube. Disturbance of this amount of fluid PCM due to tube rotation helps promote heat transfer toward the solid content in the lower region of the LHES. Furthermore, the increase in the liquid content increases the heat transfer into the liquid PCM region (upper region) due to the rotation of the tube. This, in turn, leads to a slight increase in the solid phase's melting rate, especially at the interface region. In the end, the liquid fraction will be slightly more compared to the still case.

Fig. 8 summarizes the previous actions. Fig. 8 exhibits the evolution of PCM inside LHES in cases of still and tube rotation. It is clear that both cases are congruent up to about 900 $\mathrm{s}$, which means that the same amount of PCM melted. The liquid fraction at this step is (0.04) for both cases. After this step, the melting process begins to differ in each case. The melting process is faster in still case than tube rotation case with a very little difference. At the step of $10500 \mathrm{~s}$, where the average liquid fraction is about 0.65 , an alternation in behavior occurred. At this step, the tube rotation case becomes in front till the end of the run. That is because of the disturbance just beneath the tube due to rotation. In addition, tube rotation increases slightly, transferring heat to liquid PCM, which raises its temperature. The increasing the liquid PCM temperature, the increasing the melting rate in the solid region due to heat transfer from high-temperature liquid PCM to low-temperature solid PCM. Finally, the liquid fraction of the still case and tube rotation case are 0.85 and 0.88 , respectively.

The percent enhancement between still and tube rotation cases is:

$$
\frac{0.88-0.85}{0.85} * 100 \%=3.5 \%
$$




\subsection{Agreement of Experimental and Numerical Works}

Several test points, opposite to points in the experimental work of (Fathi and Mussa, 2021), were appointed in the PCM domain. These points were used to check the agreement between the present work and the experimental work of (Fathi and Mussa, 2021). Referring to Fig. 9, the coordinates of the points are as in Table 4.

Table 4. Coordinates of test points.

\begin{tabular}{|l|l|l|l|}
\hline point & Rt $(\mathrm{mm})$ & $\theta$ degree & $\mathrm{z}(\mathrm{mm})$ \\
\hline $\mathrm{x} 2$ & 28 & 0 & 60 \\
\hline $\mathrm{y} 2$ & 28 & 45 & 120 \\
\hline $\mathrm{r} 2$ & 28 & 90 & 180 \\
\hline v2 & 28 & 135 & 240 \\
\hline s2 & 28 & 180 & 300 \\
\hline w2 & 28 & 225 & 360 \\
\hline t2 & 28 & 270 & 420 \\
\hline u2 & 28 & 315 & 480 \\
\hline
\end{tabular}

10.5.1 Still case

The temperature profiles of test points for numerical and experimental results were plotted in Fig.10. The transient temperature behavior of test points in numerical solution is similar to that of experimental results. The point $\mathrm{x} 2$ is in the lead to reach the melting temperature, followed by $\mathrm{y} 2, \mathrm{u} 2, \mathrm{t} 2$, and $\mathrm{r} 2$. The same behavior can be seen for the same points in numerical. In the experimental part, the temperature of these points settled near $80^{\circ} \mathrm{C}$ until the end of the experiment. In the numerical part, settling was at about $82^{\circ} \mathrm{C}$. In both experimental and numerical works, points $\mathrm{v} 2$ and $\mathrm{w} 2 \mathrm{had}$ the same profile and were settled between $65^{\circ} \mathrm{C}$ and $67^{\circ} \mathrm{C}$. Finally, point s2 does not reach melting temperature; this is correct for experimental and numerical works. 
Number 11 Volume 27 November $2021 \quad$ Journal of Engineering

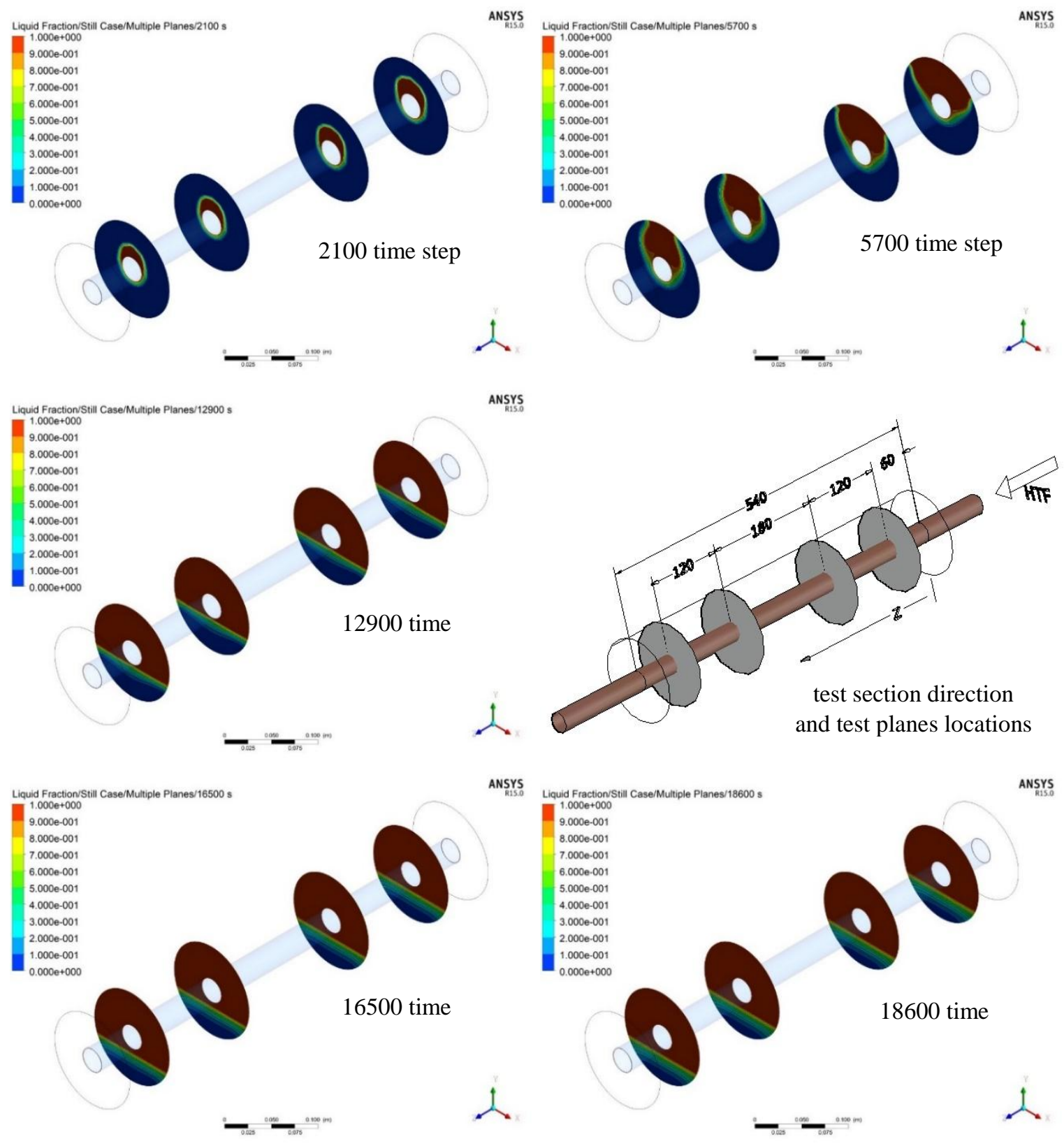

Figure 5. Contours of liquid fraction for still case at different locations. 

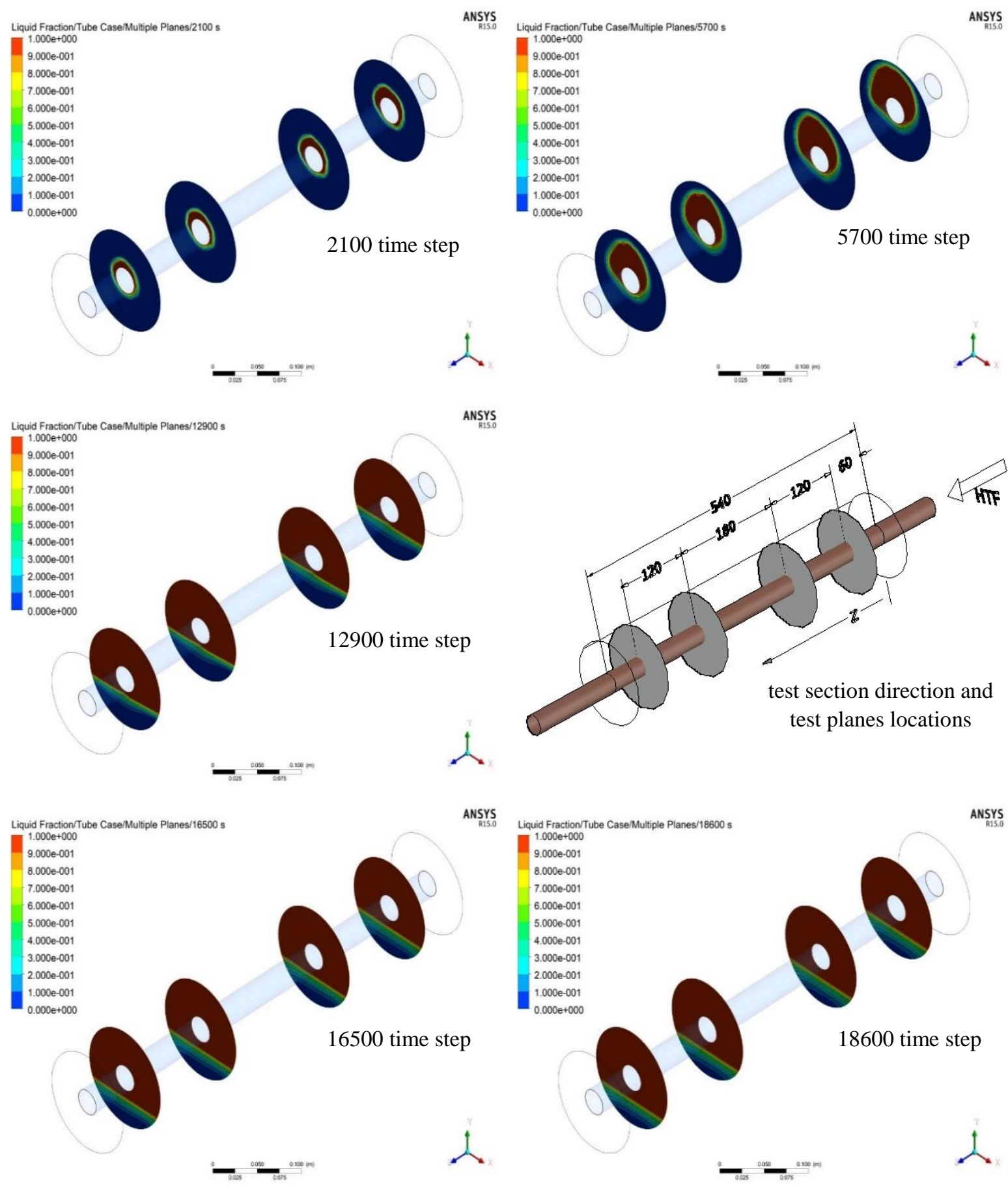

Figure 6. Contours of liquid fraction for tube rotation case at different locations. 


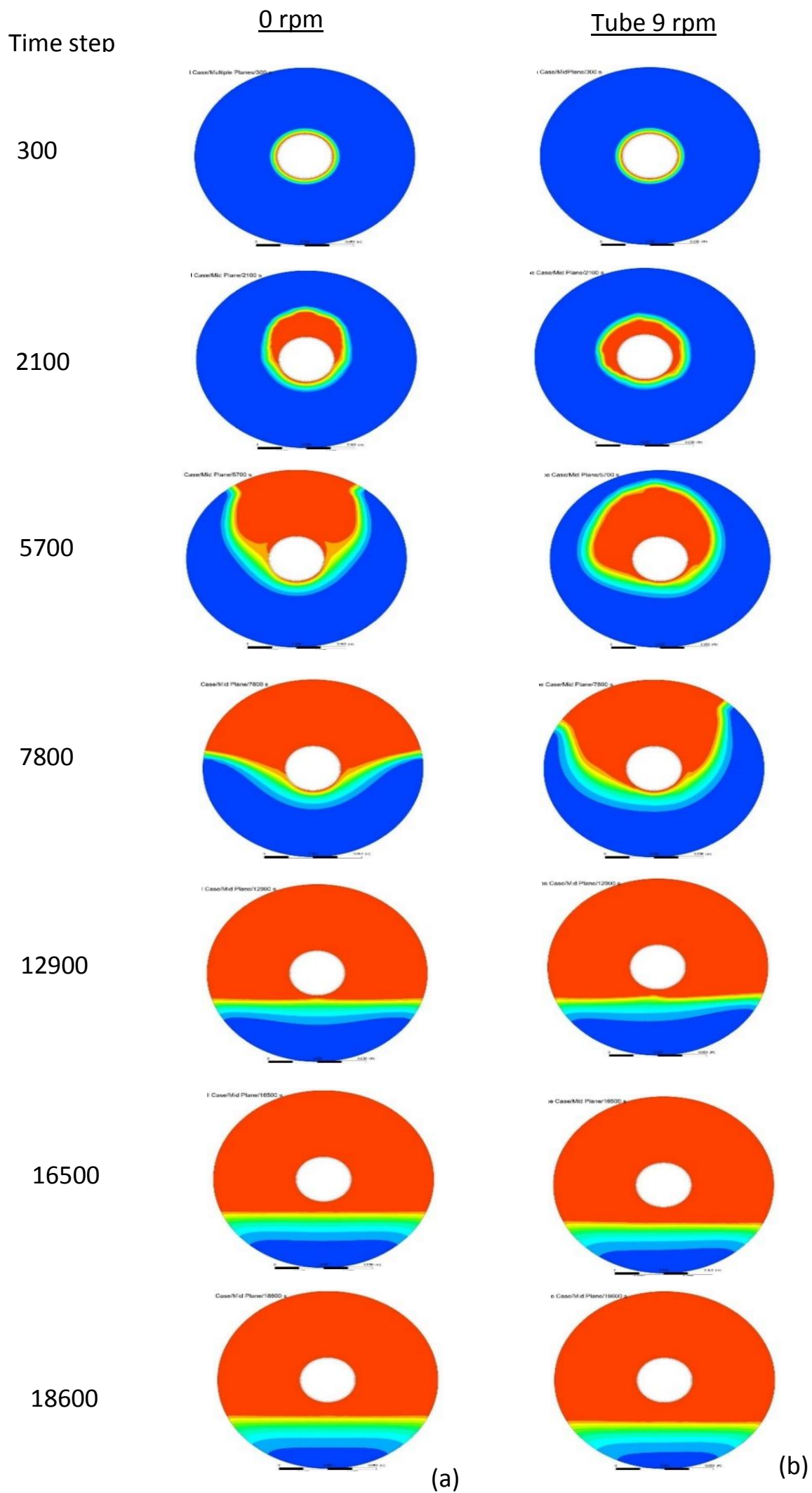

Figure 7. Average liquid fraction a) Still case. b) Tube rotation case. 


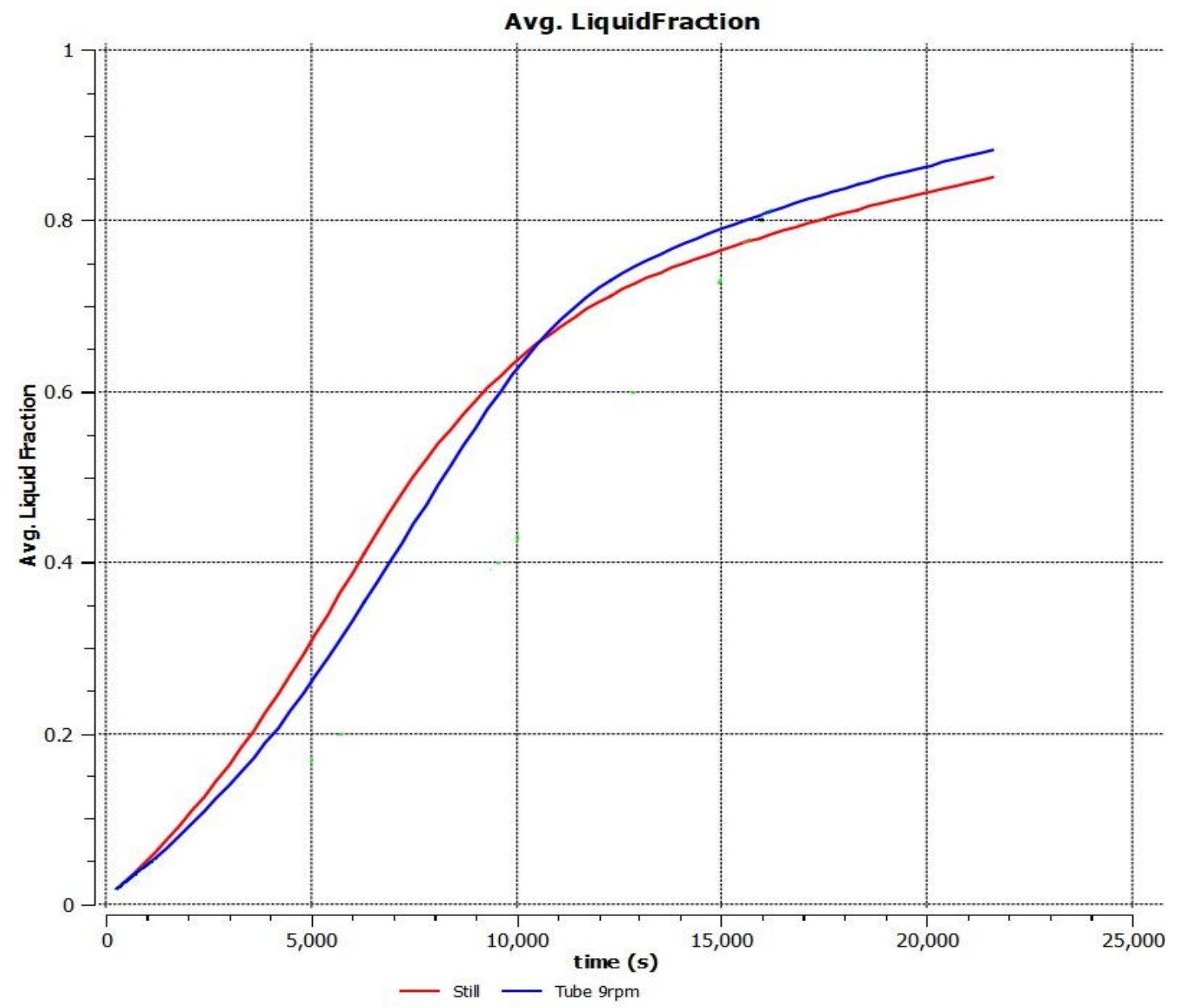

Figure 8. Transient variation of average liquid fraction for still case and tube rotation case.

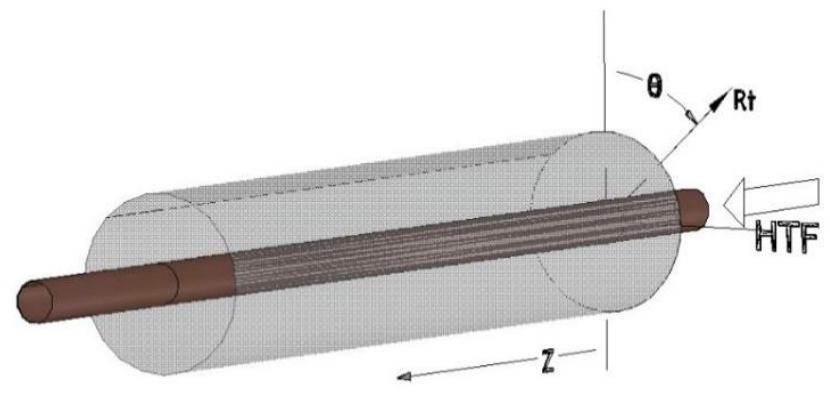

Figure 9. Coordinate system to locate the testing points. 

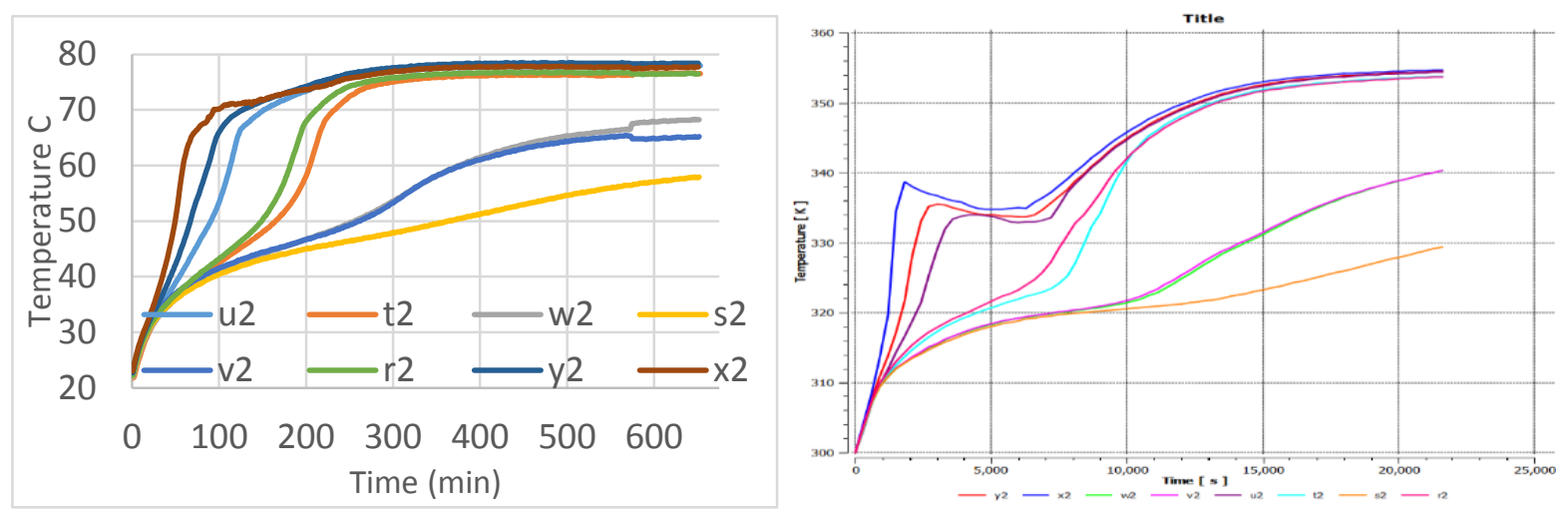

Figure 10. Comparison between numerical solution and experimental data of (Fathi and Mussa, 2021) for still case.

\subsubsection{Tube rotation case}

To check the agreement of experimental work with the numerical solution for the tube rotation case, the transient temperature variation of (Fathi and Mussa, 2021) for points $r 2$ and $\mathrm{t} 2$ on the right and left sides of the cross section, respectively, was found plotted in Fig. 11a. For points $r 2$ and t2, Fig. 11a shows that during the first $100 \mathrm{~min}$., the temperature variation with time is congruent for still and rotation cases. After $100 \mathrm{~min}$., the rotation effect begins to appear in point $r 2$ in a way different from $t 2$. In point $t 2$, temperature rise in rotation case is a little faster than still case and vice versa in point $r 2$. This behavior is similar to that in the numerical solution of the present work, as shown in Fig. 11b. Also, it agrees with the contour of temperature in Fig. 11c where the high temperature area skewed to the left with the direction of rotation. This behavior was justified earlier due to the generation of the velocity component, which is clear in Fig. 11d. This figure shows that this component is distorting the convection currents nature in the melting part of PCM. This distort is clear in Fig. 11e where the streamlines accumulated on the left side due to rotation of the HTF tube. As a result, the contour of the liquid fraction is shown in Fig. 11f. 
Number 11 Volume 27 November $2021 \quad$ Journal of Engineering
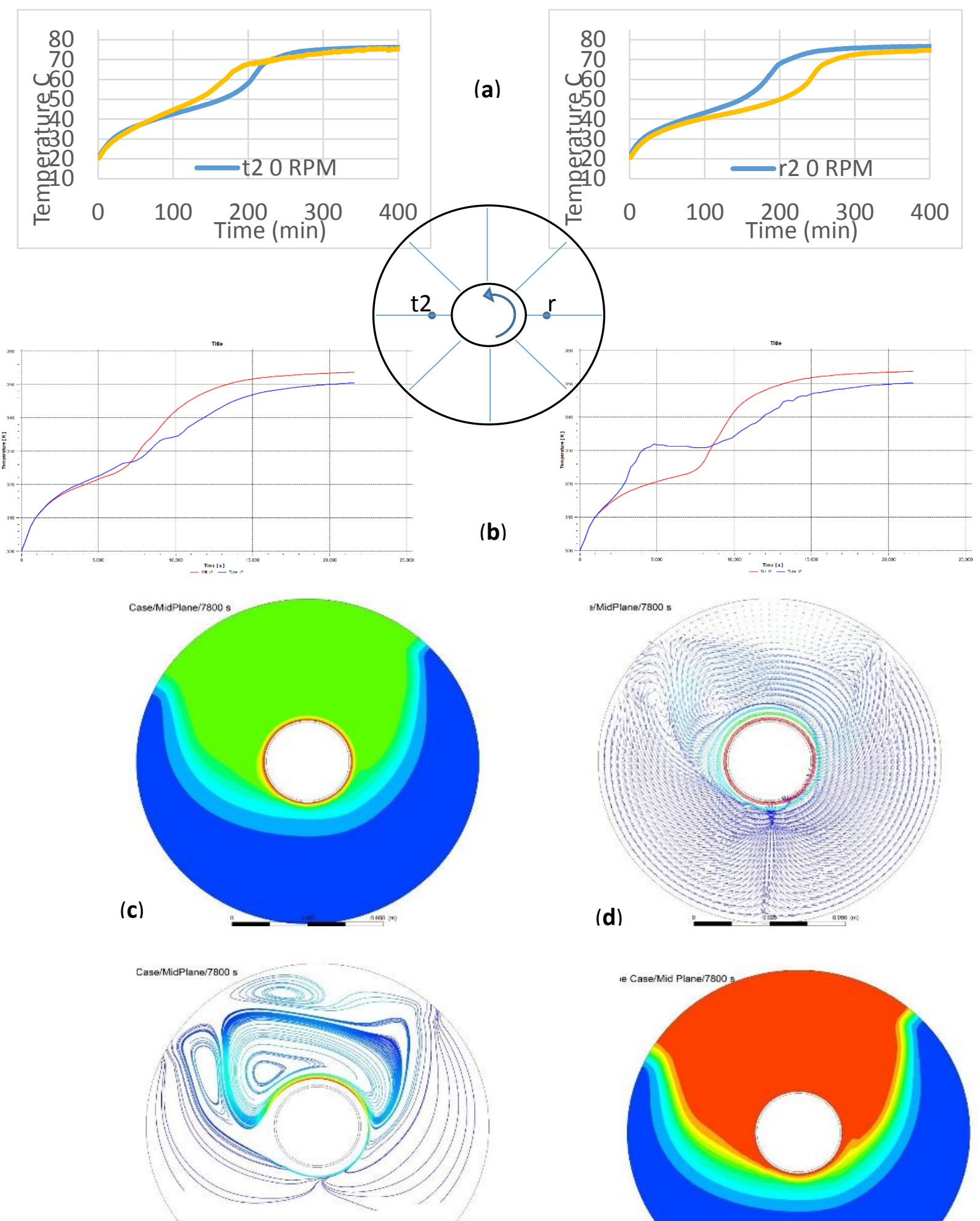

(e)
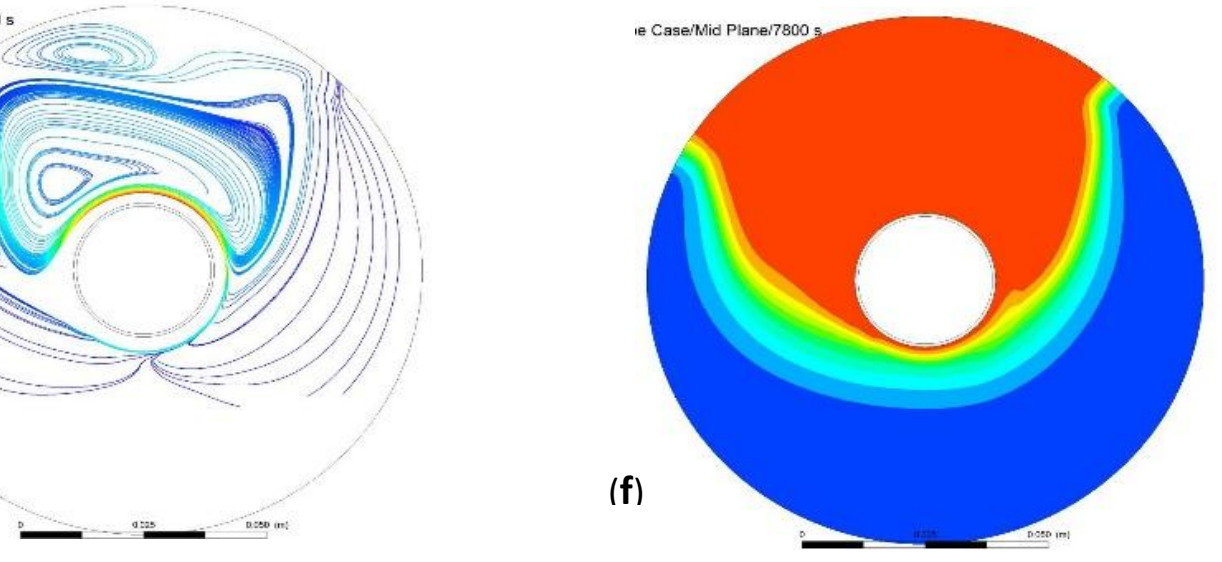

Figure 11. The behavior of right and left sides of LHES cross section. 


\section{CONCLUSIONS}

A shell and tube LHES system was numerically studied to inspect the effect of tube rotation on the melting process. The system was simulated as a 3D model. The governing equations were solved using the enthalpy-porosity method. ANSYS Fluent 15 software was employed to simulate and solve the problem. The system was studied for 9rpm tube rotation as well as still case. Paraffin wax was used as PCM while water was used as HTF which its inlet temperature was $356 \mathrm{~K}$. The following conclusions can be drawn:

* The effect of tube rotation keeps negative until melting enough amount of PCM. The tube rotation disturbs the convection currents, which decreases its effect. The convection currents skew, and consequently the liquid PCM region, to the tube rotation direction.

* When enough PCM is formed, tube rotation is positive because it helps to slightly enhance the heat transfer to liquid PCM and, consequently, to solid PCM.

* Axially heat transfer is small with respect to radially heat transfer.

* The percentage of enhancement was $3.5 \%$ for the 21600 s charging process $(6 \mathrm{hrs})$.

\section{Nomenclature}

$\begin{array}{ll}\mathrm{C}= & \text { Mushy zone constant } \\ \mathrm{C}_{\beta}= & \text { Thermal expansion } \\ \mathrm{c}_{\mathrm{p}}= & \text { Specific heat } \\ \mathrm{g}= & \text { gravity } \\ \mathrm{h}= & \text { Sensible heat } \\ \mathbf{H}= & \text { enthalpy } \\ \mathbf{I}= & \text { Identity tensor } \\ \mathrm{k}= & \text { Thermal conductivity } \\ \mathrm{L}= & \text { Latent heat } \\ \mathrm{S}= & \text { Source term } \\ \mathrm{T}= & \text { temperature } \\ \mathrm{t}= & \text { time } \\ \mathbf{v}= & \text { Velocity vector }\end{array}$

\section{Greek symbols}

$\begin{array}{ll}p= & \text { pressure } \\ B= & \text { Liquid fraction } \\ \mu= & \text { Viscosity } \\ \rho= & \text { density } \\ \omega= & \text { Angular velocity }\end{array}$

\section{Subscripts}

1

Liquid phase

liquidus The transition point from melting range (mushy zone) to liquid phase

mom momentum

pcm Property of phase change material 


\section{Number 11 Volume 27 November $2021 \quad$ Journal of Engineering}

$\begin{array}{ll}\mathrm{r} & \text { relative } \\ \mathrm{s} & \text { Solid-phase } \\ \text { solidus } & \text { Transition point to melting range (mushy zone) from solid phase } \\ \mathrm{t} & \text { transition }\end{array}$

\section{Abbreviations used}

$\begin{array}{ll}\text { HTF } & \text { Heat transfer fluid } \\ \text { LHES } & \text { Latent heat energy storage } \\ \text { PCM } & \text { phase change material }\end{array}$

\section{- REFERENCES}

- Agyenim, F., Eames, P. and Smyth, M., 2011. Experimental study on the melting and solidification behaviour of a medium temperature phase change storage material (Erythritol) system augmented with fins to power a $\mathrm{LiBr} / \mathrm{H} 2 \mathrm{O}$ absorption cooling system, Renewable Energy, Elsevier Ltd, 36(1), pp. 108-117. DOI: 10.1016/j.renene.2010.06.005.

- Akgün, M., Aydin, O. and Kaygusuz, K., 2007. Experimental study on melting/solidification characteristics of a paraffin as PCM, Energy Conversion and Management, 48(2), pp. 669-678. DOI: 10.1016/j.enconman.2006.05.014.

- Avci, M. and Yazici, M. Y., 2013, Experimental study of thermal energy storage characteristics of a paraffin in a horizontal tube-in-shell storage unit, Energy Conversion and Management. Elsevier Ltd, 73, pp. 271-277. DOI: 10.1016/j.enconman.2013.04.030.

- Aydin, O. et al., 2018. Enhancing storage performance in a tube-in shell storage unit by attaching a conducting fin to the bottom of the tube, Isi Bilimi Ve Teknigi Dergisi/ Journal of Thermal Science and Technology, 38(2), pp. 1-13.

- Ebadi, S. et al., 2018. Melting of nano-PCM inside a cylindrical thermal energy storage system: Numerical study with experimental verification, Energy Conversion and Management, Elsevier, 166(March), pp. 241-259. DOI: 10.1016/j.enconman.2018.04.016.

- Fathi, M. I., and Mussa, M. A., 2021. Experimental study on the effect of tube rotation on performance of horizontal shell and tube latent heat energy storage, Journal of Energy Storage, Elsevier Ltd, 39(April), p. 102626. DOI: 10.1016/j.est.2021.102626.

- Herrick, C. S., and Zarnoch, K. P., 1980. Heat storage capability of a rolling cylinder using Glauber's salt, International Journal of Ambient Energy, Taylor \& Francis Group, 1(1), pp. 47-55. DOI: 10.1080/01430750.1980.9675712.

- Hosseini, M. J. et al., 2012. A combined experimental and computational study on the melting behavior of a medium temperature phase change storage material inside shell and tube heat exchanger, International Communications in Heat and Mass Transfer, Elsevier Ltd, 39(9), pp. 1416-1424. DOI: 10.1016/j.icheatmasstransfer.2012.07.028. 
- Hosseini, M. J., Rahimi, M., and Bahrampoury, R., 2015. Thermal analysis of PCM containing heat exchanger enhanced with normal annular fines, Mechanical Sciences, 6(2), pp. 221-234. DOI: 10.5194/ms-6-221-2015.

- Irwan, M. A. M., Nor Azwadi, C. S., and Asako, Y., 2019. Review on Numerical Simulations for Solidification and Melting of Nano-Enhanced Phase Change Materials (NEPCM), IOP Conference Series: Earth and Environmental Science, 268(1), pp. 0-11. DOI: 10.1088/1755-1315/268/1/012114.

- Kandasamy, R., Wang, X. Q., and Mujumdar, A. S., 2007. Application of phase change materials in thermal management of electronics, Applied Thermal Engineering, 27(17-18), pp. 2822-2832. DOI: 10.1016/j.applthermaleng.2006.12.013.

- Khan, M., Zhao, N., and Xu, T., 2019. Numerical Assessment on Fin Design Parameters Employed for Augmentation of Natural Convection and Fluid Flow in a Horizontal Latent Heat Thermal Energy Storage Unit, Engineering, 11(07), pp. 407-428. DOI: 10.4236/eng.2019.117029.

- Kurnia, J. C., and Sasmito, A. P., 2018. Numerical investigation of heat transfer performance of a rotating latent heat thermal energy storage, Applied Energy, Elsevier, 227(August), pp. 542-554. DOI: 10.1016/j.apenergy.2017.08.087.

- Li, W., and Kong, C., 2014. Numerical study on the thermal performance of a shell and tube phase change heat storage unit during melting process, Advances in Mechanical Engineering, 2014. DOI: 10.1155/2014/360283.

- Miró, L., Gasia, J., and Cabeza, L. F., 2016. Thermal energy storage (TES) for industrial waste heat (IWH) recovery: A review, Applied Energy, 179, pp. 284-301. DOI: 10.1016/j.apenergy.2016.06.147.

- Nadeem, F. et al., 2019. Comparative review of energy storage systems, their roles, and impacts on future power systems, IEEE Access. IEEE, 7(c), pp. 4555-4585. DOI: 10.1109/ACCESS.2018.2888497.

- Regin, A. F., Solanki, S. C., and Saini, J. S., 2006. Latent heat thermal energy storage using cylindrical capsule: Numerical and experimental investigations, Renewable Energy, 31(13), pp. 2025-2041. DOI: 10.1016/j.renene.2005.10.011.

- Selimefendigil, F., and Öztop, H. F., 2020. Mixed convection in a PCM filled cavity under the influence of a rotating cylinder, Solar Energy, Elsevier, 200(March), pp. 61-75. DOI: 10.1016/j.solener.2019.05.062.

- Senthil, R., and Cheralathan, M., 2016. Melting and Solidification of Paraffin Wax in a Concentric Tube PCM Storage for Solar Thermal Collector, International Journal of Chemical, 14(4), pp. 2634-2640. Available at: http://www.tsijournals.com/abstract/melting-and-solidification-of-paraffin-waxin-a-concentric-tube-pcm-storage-for-solar-thermal-collector-12762.html.

- Sharma, A. et al., 2009. Review on thermal energy storage with phase change materials and applications, Renewable and Sustainable Energy Reviews, 13(2), pp. 318-345. DOI: 10.1016/j.rser.2007.10.005.

- Soibam, J., 2017. Numerical Investigation of a Heat Exchanger using Phase Change Materials (PCMs), (October). 